\title{
Nurses Performance Regarding Fluid, Electrolytes and Acid Base Imbalances for Neonates and Pediatrics at Pediatric Hospital Assiut University
}

\author{
Thoria Hassan Abd Elfatah ${ }^{1}$, Mona Aly Mohammed ${ }^{2}$, Mogedda Mohamed Mehany ${ }^{3}$. \\ 1. Clinical Nursing Specialist, Neonatal Intensive Care Unit Children Hospital, Assuit University, Assuit, Egypt. \\ 2. Assistant professor of critical care and emergency nursing Faculty of Nursing, Assuit, University, Assuit, Egypt. \\ 3. Assistant professor of critical care and emergency nursing Faculty of Nursing Assiut, University, Assuit, Egypt.
}

\begin{abstract}
Background: Aim of the study was to assess the nurses' performance regarding fluid, electrolytes and acid base imbalances for pediatrics and neonates. Research design: A descriptive research design was used. Setting this study was carried out in the paediatric and neonate intensive care at Assuit university paediatric hospital .Study sample consisted of all available nursing staff (130) nurses above mentioned setting.Tools were utilized for data collection: First tool nurses knowledge assessment tool, Second tool Nurses practice assessment tool. Results: The result of this study found that the majority of studied nurses were at the age group of 25 to $<30$, females, married, and 58.5\% were secondary school of nursing. Nearly half $(47.7 \%)$ of studied nurses were having poor level of knowledge regarding fluid, electrolytes and acid base imbalances, and more than half(69.2\%) of studied nurses have good level of performance, there were statistically significant difference between knowledge and practice of studied nurses regarding fluid, electrolytes and acid base imbalances. Conclusion: The general score of nurse poor level of knowledge and good level of practice regarding fluid, electrolytes, and acid base imbalances. Recommendations Provide in-service training programs for nurses to improve their performance regarding fluid, electrolytes and acid base imbalances.
\end{abstract}

\section{Key words: Performance, Fluid, Electrolytes, Acid Base \& Imbalances.}

\section{Introduction}

Fluid and electrolytes are vital to life; adequate balance is importance to maintain healthy function of the body. Fluid and electrolytes are involved in almost every cellular reaction and function. Chemical reactions that occur in the body depend on a careful acid and base balance (Taylor et al., 2015).

Fluids are considered the cornerstone of therapy for many shock states, particularly states that are associated with relative or absolute hypovolemia. Fluids are also commonly used for many other purposes, such as renal protection from endogenous and exogenous substances (Bruno et al., 2015).

Electrolytes are a major component of body fluids that play vital roles in maintaining chemical balance, there are six major electrolytes; sodium, potassium, calcium, chloride, phosphorus, and magnesium (Kamil et al., 2011).

Electrolyte balance is maintained by oral, or in emergencies, intravenous intake of electrolytecontaining substances, and is regulated by hormones, in general with the kidneys flushing out excess levels. In humans, electrolyte homeostasis is regulated by hormones such as antidiuretic hormones, aldosterone and parathyroid hormones (McMillen \& Pitcher, 2010).

Acid-base balance is a reflection of the $\mathrm{pH}$ level. The $\mathrm{pH}$ is the measurement of the acidity or alkalinity of any fluid and is recorded on a scale from 1 to 14 . A fluid with a $\mathrm{pH}$ of 7 is considered neutral.
The $\mathrm{pH}$ of blood falls within a narrow range of 7.357.45. This range is essential for the body systems to function properly (Verma \& Paul, 2010).

If the $\mathrm{PH}$ goes outside the normal range, enzymes within cells do not function properly; hemoglobin does not manage oxygen properly; and serious physiological problems occur (Ayers \& Dixon, 2012).

The body normally maintains a steady balance between the acids produced during normal metabolism and the bases that neutralize and promote the excretion of the acids. Their regulation is necessary to maintain homeostasis and acid-base balance. Many health problems may lead to acid-base imbalances. Patients with diabetes mellitus, chronic obstructive pulmonary disease, and kidney disease frequently develop acid-base imbalances (Boron \& Boulpaep, 2012).

Acidosis result from accumulation of acids or loss of bases, both of which cause abnormal increases in the hydrogen ion concentrations of body fluids. Conversely, alkalosis results from a loss of acids or an accumulation of bases accompanied by a decrease in hydrogen ion concentrations (Shier \& Lewis, 2010).

The nurse caring for a particular patient is responsible for ensuring that fluid balance charts are recorded regularly and with accuracy. To promote adequate hydration, safe and effective nursing care, nurses 
should always report any significant abnormalities identified in patients' fluid record (Shepherd, 2011). The Nurses knowledge about the administration of fluid and electrolytes is most important to prevent the patient from the complication and assurance of the quality of care among the Patients (Eastwood et al., 2012).

The knowledge and practices of nurses about fluid monitoring and electrolytes administration is necessary to provide the good quality of patient care and this is the responsibility of all registered nurses to closely observe and monitoring fluid balance (Vijayan, 2011).

Proper and accurate documentation of intake fluid and output is essential to prevent the complications of fluid imbalance in critically ill patients. Inaccuracy in monitoring and recording of fluid and electrolytes may lead to the poor management (Diacon \& Bell, 2012)

Assessing patients for fluid, electrolyte, and acid-base imbalances is an important part of nursing practice. Clinical an important part of nursing practice. In addition to assessing the imbalances of fluid, electrolyte and acid base require to obtain subjective and objective data from any patient with suspected fluid, electrolyte, or acid-base imbalances, To make a competent assessment of fluid balance, nurses need to understand the fluid compartments within the body and how fluid moves between these compartments(Davies, 2010).

Fluid balance monitoring is an essential part of the process of care of critically ill patients. Fluid Balance is the balancing of intake and output of fluid to permit metabolic processes to function correctly. Maintaining fluid balance plays an important role in the managing critically ill patients. The accurate monitoring of fluid balance activities is a vital part of patient's baseline information, which guides medical and nursing interventions to achieve physiological stability. Inaccurate monitoring of fluid balance especially in critically ill patients can deteriorate patient's conditions. Therefore, fluid balance should be monitored and recorded accurately for patients in intensive care units (Asfour, 2016).

\section{Aims of the study}

To assess the nurses' performance regarding fluid, electrolytes and acid base imbalances for pediatrics and neonates at Assiut University pediatrics Hospital.

\section{Research Question}

1- What is the nurses' knowledge regarding fluid, electrolytes and acid base imbalances?

2- What is the level of nurses' practice regarding fluid, electrolytes and acid base imbalances?

\section{Subjects \& Methods \\ Research Design}

A descriptive research design was used to achieve the aim of the study.

Setting

This study conducted in two intensive care units (neonate and paediatric intensive care unit) at Assuit University paediatric Hospital.

\section{Sample}

The study sample consisted of all nurses who were available and agreed to participate in the study. The sample size was 130 nursing staff (30) baccalaureate degree, (24) technical nurses and (76) secondary school are working at the neonate intensive care unit and paediatric intensive care unit.

\section{Tools of the study}

Two tools were used in this study and were developed by the researcher to collect the necessary data after reviewing national and international literature under guidance of supervisors.

\section{Tool I : Nurses' knowledge Assessment tool}

This tool was developed by the researcher after reviewing national and international literature to assess the nurses' knowledge about fluid, electrolytes and acid base imbalances and it include two parts as the following:

Part 1: Demographic data of the studied nurses It was developed to assess the nurses' demographic characteristics. It included age, sex, qualification, place of work, total years of nursing experience, and total years of Intensive care unit experience, attendance of training program about fluid, electrolyte and acid base imbalances and place of living.

Part 2: Structured knowledge questionnaire The structured knowledge questionnaire was developed by researcher after reading national and international literature to collect the data to assess the knowledge of nurses about fluid, electrolytes and acid base imbalances. The structured knowledge questionnaire consist of 43 questions which consist of three parts.

Part 1 about fluid and include fluid balance, fluid imbalance, intravenous solutions and fluid secretion.

Part 2 about electrolytes which include functions of electrolyte, types of electrolyte, normal values of electrolyte, electrolyte imbalances and precautions during giving intravenous calcium.

Part3 about Acid base which include normal value of acid basePH,Paco2, and $\mathrm{Hco} 3$, indication of blood gas analysis, Arterial puncture sites, complication of arterial puncture and acid base imbalances.

Scoring system of nurse's knowledge assessment tool:

For multiple choice questions and true or false questions one grade for correct answer and zero for 
incorrect answer, for list questions, one grade for correct point and zero for incorrect point. Total numbers of question were 43 ; total numbers of grade were 63 , and categorized as

$$
\begin{array}{ll}
- & <50 \% \text { Poor } \\
\text { - } & 50-60 \% \text { Fair } \\
\text { - } & >60 \% \text { Good }
\end{array}
$$

Tool II: Nurses' performance assessment tool

This tool was regarding fluid, electrolytes and acid base imbalances in form of structured observational checklist which includes these procedures (Intravenous Cannulation, Monitoring Fluid Balance, Infusion pump, Iv Infusion, CVP Care and Measurement, Nursing Precautions for Patients Receiving Intravenous Calcium, Potassium and Magnesium).

Scoring system of nurses' performance assessment tool:

Each items was observed, categorized and scored into two grade for done correctly, one grade for done incorrect and zero for not done total number of grade were 240 , and categorized as

$$
\begin{array}{ll}
- & <50 \% \text { Poor } \\
\text { - } & 50-60 \% \text { Fair } \\
- & >60 \% \text { Good }
\end{array}
$$

Technique for data collection

1-Preparatory phase

1-Ethical considerations

- Research proposal were approved from Ethical Committee in the Faculty of Nursing.

- There was no risk for study nurses during application of the research.

- The study was followed common ethical principles in clinical research.

- Oral consent was obtained from the nurses that were participated in the study, after explaining the nature and purpose of the study.

- Confidentiality and anonymity was assured.

- Study nurses had the right to refuse to participate and or withdraw from the study without any rational any time.

- Study subject privacy was considered during collection of data.

2- An official permission obtained from the chairman of intensive care units to carry the present research after explain the aim of the study.

3- A review of national and international related literature in the various aspects of the problem using books, articles, periodicals, magazines and websites was done.

4-The tools were developed after comprehensive literature review.

Validity of the tool

Content validity was established by panel of 5 expertise's from medical and nursing staff who reviewed the tools of data collection for clarity, relevance, comprehensiveness, understanding, applicability and easiness.

Pilot Study

A pilot study was carried out to test the feasibility and practicability of the study tools on $10 \%$ of sample (about 13 nurses) from total sample.

Reliability of the tool

Coefficient alpha/ Cronbach'salpha AlphaCronbach's test for tools1 (knowledge) which P value was 0.821 and for tool 2(practice) was 0.790 which were acceptable.

\section{2- Implementation phase}

- Once permission was granted to proceed with the proposed study, the researcher initiated data collection. The head nurses of hospital department who help the researcher to accomplish this work.

- Data was collected at Assiut university pediatric hospital.

- At begging of interview the researcher was introduce herself to initiate line of communication.

- Interview questionnaire sheet: Filled through interviewing of each nurse separately. The purpose of the study was explained to the each nurse prior to answering the questions using tool one (1st and 2 nd parts).

- Data were collected from intensive care unit and neonate intensive care unit at Assiut University paediatrics Hospital during the period seven months.

- An observational check list: Was carried out to the nurses during their work in the morning and afternoon shift and were carried without the nurses attention by using tool 2 to assess the level of performance during nurses' procedure.

\section{3-Evaluation phase}

The nurses was assessed in morning and afternoon shift to assess the level of performance by using tools and was determine the scoring system for checklist.

Statistical analysis:

Data entry and data analysis were done using SPSS version 19 (Statistical Package for Social Science). Data were presented as number, percentage, mean, standard deviation. Chi-square test was used to compare between qualitative variables. P-value considered statistically significant when $\mathrm{P}<0.05$. 


\section{Results}

Table (1): Demographic characteristics of the studied nurses: $(n=130)$.

\begin{tabular}{|c|c|c|}
\hline variables & No. $(n=130)$ & $\%$ \\
\hline \multicolumn{3}{|l|}{ Age: (years) } \\
\hline$<25$ & 31 & 23.8 \\
\hline $25-<30$ & 77 & 59.2 \\
\hline$\geq 30$ & 22 & 16.9 \\
\hline Mean \pm SD & \multicolumn{2}{|c|}{$27.18 \pm 4.67$} \\
\hline Range & \multicolumn{2}{|c|}{$20.0-52.0$} \\
\hline \multicolumn{3}{|l|}{ Sex: } \\
\hline Male & 1 & 0.8 \\
\hline Female & 129 & 99.2 \\
\hline \multicolumn{3}{|l|}{ Marital status: } \\
\hline Single & 52 & 40.0 \\
\hline Married & 78 & 60.0 \\
\hline \multicolumn{3}{|l|}{ Residence: } \\
\hline Rural & 52 & 40.0 \\
\hline Urban & 78 & 60.0 \\
\hline \multicolumn{3}{|l|}{ Qualifications: } \\
\hline Bachelor of Nursing & 30 & 23.1 \\
\hline Technical Nursing Institute & 24 & 18.5 \\
\hline Secondary School of Nursing & 76 & 58.5 \\
\hline \multicolumn{3}{|l|}{ Years of experience in nursing: } \\
\hline$<5$ & 45 & 34.6 \\
\hline $5-10$ & 41 & 31.5 \\
\hline$>10$ & 44 & 33.8 \\
\hline Mean \pm SD & \multicolumn{2}{|c|}{$8.16 \pm 6.03$} \\
\hline Range & \multicolumn{2}{|c|}{$1.0-33.0$} \\
\hline \multicolumn{3}{|l|}{ Years of experience in ICU: } \\
\hline$<5$ & 47 & 36.2 \\
\hline $5-10$ & 40 & 30.8 \\
\hline$>10$ & 43 & 33.1 \\
\hline Mean \pm SD & \multicolumn{2}{|c|}{$8.02 \pm 6.05$} \\
\hline Range & \multicolumn{2}{|c|}{$1.0-33.0$} \\
\hline \multicolumn{3}{|c|}{ Study fluid imbalance, electrolyte and acid base Under graduation } \\
\hline Yes & 31 & 23.8 \\
\hline No & 99 & 76.2 \\
\hline \multicolumn{3}{|l|}{ Attending training courses: } \\
\hline Yes & 6 & 4.6 \\
\hline No & 124 & 95.4 \\
\hline \multicolumn{3}{|l|}{ Duration of course: } \\
\hline$<3$ days & 3 & 50.0 \\
\hline $3-6$ days & 3 & 50.0 \\
\hline \multicolumn{3}{|l|}{ Place of course: } \\
\hline Inside the hospital & 0 & 0.0 \\
\hline Outside the hospital & 6 & 100.0 \\
\hline
\end{tabular}






Figure (1): Percentage distribution of studied nurses according to Years of experience in nursing.

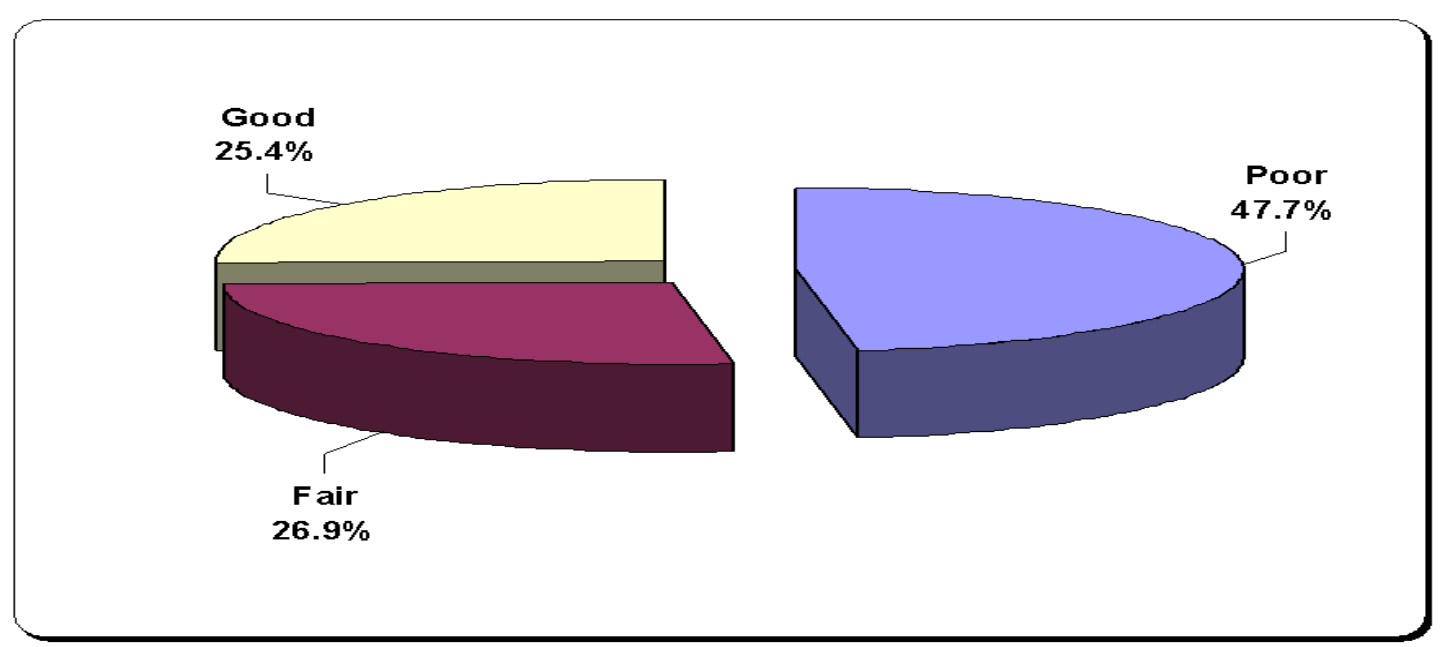

Figure (2): Percentage Distribution of nurses according to their total level of knowledge on fluid, electrolytes and acid base.

Table (2): Mean score distribution of studied nurses' practice regarding care of patients with fluid, electrolytes and acid base imbalances.

\begin{tabular}{|c|c|c|}
\hline Procedures & Total score & Mean \pm SD \\
\hline Intravenous cannulation & 66 & $55.56 \pm 12.96$ \\
\hline IV infusion & 42 & $32.47 \pm 8.57$ \\
\hline Infusion pump & 20 & $15.21 \pm 6.78$ \\
\hline Monitoring fluid balance & 22 & $17.67 \pm 7.28$ \\
\hline C.V.P Care & 32 & $23.69 \pm 7.10$ \\
\hline Nursing precautions for patients receiving calcium gluconate & 36 & $27.72 \pm 9.01$ \\
\hline Nursing Consideration for Intravenous potassium replacement & 16 & $12.04 \pm 4.21$ \\
\hline Nursing Consideration for Intravenous Magnesium Replacement & 6 & $3.84 \pm 2.73$ \\
\hline Total score of nurses' practices & 240 & $188.02 \pm 58.64$ \\
\hline
\end{tabular}


Table (3): Mean score distribution of studied nurses about fluid, electrolytes and acid base: $(\mathbf{n}=130)$.

\begin{tabular}{|l|c|c|c|}
\hline \multicolumn{1}{|c|}{ Items of nurses knowledge } & $\begin{array}{c}\text { Max. } \\
\text { score }\end{array}$ & Mean \pm SD & Range \\
\hline Fluids: & $\mathbf{2 2}$ & $\mathbf{1 0 . 6 8} \pm \mathbf{2 . 8 7}$ & $\mathbf{5 . 0}-\mathbf{1 7 . 0}$ \\
\hline Normal human body distribution of fluid. & 7 & $3.56 \pm 1.62$ & $1.0-7.0$ \\
\hline Organs of hemostasis & 2 & $1.43 \pm 0.54$ & $0.0-2.0$ \\
\hline Types of IV solutions & 5 & $1.75 \pm 1.23$ & $0.0-5.0$ \\
\hline Hypovolemia & 6 & $2.37 \pm 1.32$ & $0.0-6.0$ \\
\hline Hypervolemia & 2 & $1.56 \pm 0.66$ & $0.0-2.0$ \\
\hline Electrolytes: & $\mathbf{3 0}$ & $\mathbf{1 0 . 9 8} \pm \mathbf{4 . 4 7}$ & $\mathbf{2 . 0}-\mathbf{2 2 . 0}$ \\
\hline Normal values of electrolytes & 3 & $1.54 \pm 1.06$ & $0.0-3.0$ \\
\hline Types of electrolytes & 7 & $3.93 \pm 1.89$ & $0.0-7.0$ \\
\hline Functions of electrolytes & 7 & $0.59 \pm 0.70$ & $0.0-2.0$ \\
\hline Signs and symptoms of electrolytes disturbances & 13 & $4.92 \pm 2.42$ & $1.0-13.0$ \\
\hline Acid base: & $\mathbf{1 1}$ & $\mathbf{5 . 9 5} \pm \mathbf{2 . 0 6}$ & $\mathbf{0 . 0}-\mathbf{1 1 . 0}$ \\
\hline Organs of hemostasis & 3 & $1.95 \pm 0.82$ & $0.0-3.0$ \\
\hline Normal values of ABG & 3 & $1.35 \pm 0.86$ & $0.0-3.0$ \\
\hline Acid base abnormality & 5 & $2.65 \pm 1.11$ & $0.0-5.0$ \\
\hline Total & $\mathbf{6 3}$ & $\mathbf{2 7 . 8 6 \pm 7 . 3 9}$ & $\mathbf{1 2 . 0}-\mathbf{4 8 . 0}$ \\
\hline
\end{tabular}

Table (4): Relation between demographic characteristics of nurses and their knowledge regarding fluid, electrolytes and acid base imbalances.

\begin{tabular}{|c|c|c|c|c|}
\hline \multirow[t]{2}{*}{ Items } & Fluids & Electrolytes & Acid base & $\begin{array}{c}\text { Knowledge } \\
\text { score }\end{array}$ \\
\hline & Mean \pm SD & Mean \pm SD & Mean \pm SD & Mean \pm SD \\
\hline \multicolumn{5}{|l|}{ Age: (years) } \\
\hline$<25$ & $10.26 \pm 2.74$ & $10.26 \pm 3.82$ & $5.74 \pm 2.52$ & $26.58 \pm 6.12$ \\
\hline $25-<30$ & $11.05 \pm 3.05$ & $11.49 \pm 4.85$ & $6.12 \pm 1.92$ & $29.00 \pm 7.99$ \\
\hline$\geq 30$ & $9.95 \pm 2.21$ & $10.18 \pm 3.81$ & $5.68 \pm 1.86$ & $25.68 \pm 6.25$ \\
\hline$P$-value & 0.209 & 0.356 & 0.493 & 0.155 \\
\hline \multicolumn{5}{|l|}{ Marital status: } \\
\hline Single & $11.46 \pm 2.73$ & $11.12 \pm 4.13$ & $6.33 \pm 2.44$ & $29.12 \pm 6.97$ \\
\hline Ever-married & $10.15 \pm 2.86$ & $10.88 \pm 4.71$ & $5.71 \pm 1.74$ & $27.03 \pm 7.59$ \\
\hline P-value & 0.228 & 0.100 & 0.545 & 0.101 \\
\hline \multicolumn{5}{|l|}{ Residence: } \\
\hline Rural & $11.35 \pm 2.74$ & $10.54 \pm 4.50$ & $6.13 \pm 2.23$ & $28.31 \pm 7.66$ \\
\hline Urban & $10.23 \pm 2.88$ & $11.27 \pm 4.46$ & $5.83 \pm 1.94$ & $27.56 \pm 7.24$ \\
\hline P-value & 0.121 & 0.425 & 0.320 & 0.541 \\
\hline \multicolumn{5}{|l|}{ Qualifications: } \\
\hline Bachelor of Nursing & $14.17 \pm 1.64$ & $15.03 \pm 3.88$ & $7.90 \pm 1.45$ & $37.33 \pm 4.87$ \\
\hline Technical Nursing Institute & $10.25 \pm 1.96$ & $8.83 \pm 3.68$ & $5.21 \pm 2.21$ & $24.54 \pm 5.46$ \\
\hline Secondary School of Nursing & $9.43 \pm 2.33$ & $10.05 \pm 3.94$ & $5.42 \pm 1.74$ & $25.17 \pm 5.38$ \\
\hline P-value & $0.000^{*}$ & $0.000^{*}$ & $0.000^{*}$ & $0.000^{*}$ \\
\hline \multicolumn{5}{|l|}{ Years of experience in nursing: } \\
\hline$<5$ & $12.44 \pm 2.78$ & $12.71 \pm 4.90$ & $6.93 \pm 2.10$ & $32.40 \pm 8.08$ \\
\hline $5-10$ & $10.00 \pm 2.61$ & $10.41 \pm 4.04$ & $5.41 \pm 2.00$ & $26.07 \pm 5.71$ \\
\hline$>10$ & $9.50 \pm 2.32$ & $9.73 \pm 3.90$ & $5.45 \pm 1.72$ & $24.89 \pm 5.76$ \\
\hline P-value & $0.000 *$ & $0.015^{*}$ & $0.000 *$ & $0.000^{*}$ \\
\hline \multicolumn{5}{|l|}{ Years of experience in ICU: } \\
\hline$<5$ & $12.38 \pm 2.74$ & $12.55 \pm 4.86$ & $6.89 \pm 2.11$ & $32.11 \pm 8.04$ \\
\hline $5-10$ & $9.95 \pm 2.62$ & $10.43 \pm 4.09$ & $5.35 \pm 1.98$ & $26.03 \pm 5.77$ \\
\hline$>10$ & $9.49 \pm 2.34$ & $9.77 \pm 3.93$ & $5.49 \pm 1.72$ & $24.93 \pm 5.82$ \\
\hline
\end{tabular}




\begin{tabular}{|l|c|c|c|c|}
\hline \multirow{2}{*}{ Items } & Fluids & Electrolytes & Acid base & $\begin{array}{c}\text { Knowledge } \\
\text { score }\end{array}$ \\
\cline { 2 - 5 } & Mean \pm SD & Mean \pm SD & Mean \pm SD & Mean \pm SD \\
\hline P-value & $0.000^{*}$ & $0.028^{*}$ & $0.000^{*}$ & $0.000^{*}$ \\
\hline $\begin{array}{l}\text { Study fluid imbalance, } \\
\text { electrolyte and acid base: }\end{array}$ & & & & \\
\hline Yes & $12.74 \pm 2.45$ & $11.42 \pm 4.46$ & $6.74 \pm 2.65$ & $31.19 \pm 8.35$ \\
\hline No & $10.03 \pm 2.69$ & $10.84 \pm 4.49$ & $5.71 \pm 1.79$ & $26.82 \pm 6.78$ \\
\hline $\boldsymbol{P}$-value & $0.000^{*}$ & 0.515 & $0.016^{*}$ & $0.010^{*}$ \\
\hline Attending training courses: & & & & \\
\hline Yes & $9.83 \pm 3.43$ & $8.67 \pm 2.07$ & $4.50 \pm 1.64$ & $23.50 \pm 4.59$ \\
\hline No & $10.72 \pm 2.85$ & $11.09 \pm 4.53$ & $6.02 \pm 2.06$ & $28.07 \pm 7.45$ \\
\hline $\boldsymbol{P}$-value & 0.528 & 0.122 & 0.058 & 0.110 \\
\hline
\end{tabular}



Figure (3): percentages Distribution of studied nurses' practices regarding total procedures of fluid, electrolytes and acid base.

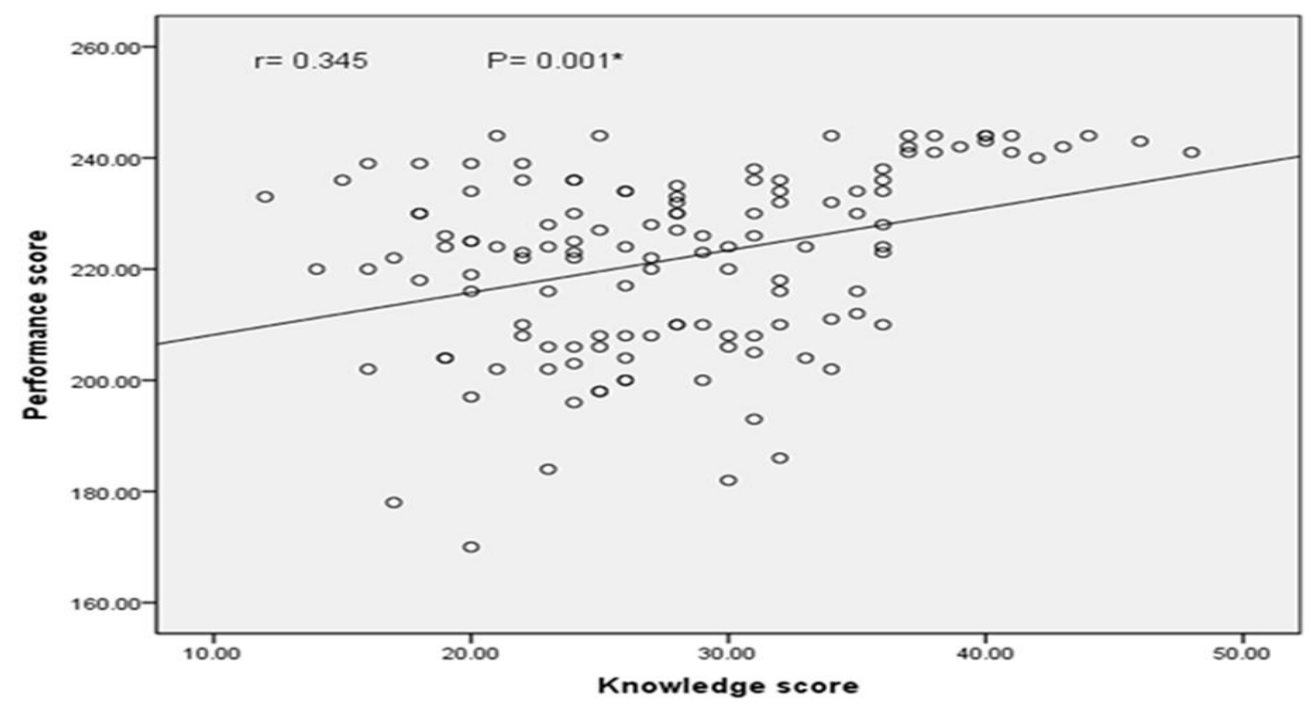

Figure (4): Correlation between nurses' knowledge score and their practices level 
Table (1) \& figure (1): Shows Socio-demographic characteristics of studied nurses. It observed that the majority of studied nurses $(59.2 \%)$ were at the age group of $25-<30$ with a mean age of $27.18 \pm 4.67$ and $(23.8 \%)$ were at the age group of $<25$ years and only (16.9\%) of studied nurses' age ranged had >30years. As regarding sex the majority of studied nurses 99.2\% were females. As regarding marital status more than half of studied nurses $(60 \%)$ were married, and living in urban areas (60.0\%), where having a secondary school of nursing $(58.5 \%)$. As regarding years of experience in nursing and in ICU it observed that the $(34.6 \%)$ in years of experience in nursing with a mean age of $8.16 \pm 6.03$ and $(36.2 \%)$ in years of experience in ICU with a mean age of $8.02 \pm 6.05$ were at the age group of $<5$ years.it observed that the majority of studied nurses $(76.2 \%)$ had no study fluid imbalances, electrolyte and acid base and (95.4\%) had no previous training courses about fluid, electrolyte and acid base and only (4.6\%) attending training course outside the hospital.

Table (2): Show nurses' practice about care of patients with fluid, electrolytes and acid base imbalances. It's apparent from this table that total practice score of care of patients with fluid, electrolytes and acid base imbalances of studied nurses were 240 with Mean \pm SD 188.02 \pm 58.64 practices about Intravenous cannulation, IV infusion, Infusion pump, Monitoring fluid balance, C.V.P Care, Nursing precautions for patients receiving calcium gluconate, Nursing Consideration for Intravenous potassium replacement and Nursing Consideration for Intravenous Magnesium Replacement were with Mean \pm SD $(55.56 \pm 12.96$, $32.47 \pm 8.57,15.21 \pm 6.78,17.67 \pm 7.28,23.69 \pm$ $7.10,27.72 \pm 9.01,12.04 \pm 4.21$ and $3.84 \pm 2.73$ ) respectively.

Table (3): Show nurses' knowledge about fluid, electrolytes and acid base imbalances. It's apparent from this table that total knowledge score of fluid, electrolytes and acid base imbalances of studied nurses were 63 with mean \pm SD $27.86 \pm 7.39$ with range 12.0 - 48.0, knowledge about fluid, electrolytes and acid base were with mean \pm SD (10.68 \pm 2.87 , $10.98 \pm 4.47$ and $5.95 \pm 2.06$ ) respectively

Table (4): Show that were statistically significant difference of knowledge of studied nurses and their Qualifications, Years of experience in nursing and ICU and Study fluid imbalance, electrolytes and acid base.

Figure (2): Show nearly half of studied nurses were having poor level of knowledge regarding fluid, electrolytes and acid base.

Figure (3): Shows more than half of studied nurses were having good level of practice.
Figure (4): Show that there was a statistically significant difference and significant positive correlation between knowledge score and performance score $(\mathrm{r}=0.345 \& \mathrm{P}=0.001)$.

\section{Discussion}

The result of the present study showed the majority of studied nurses were at the age group between 25$<30$ years, females, and married, secondary school of nursing is the highest proportion, and years of experience in nursing and ICU less than 5 years. This result agree with (Vijayan, 2011) who told that "the majority of studied nurses their age ranged from 2335 years $(70 \%)$, 95\% female, years of experience in nursing are $1-5$ years $(42.55 \%)$ and $1-5$ years about (55\%)ICU experience.

The results of the present study show nearly half have poor knowledge, more than quarter have fair knowledge and only one quarter had good knowledge scores regarding total items of knowledge. Because nurses play important roles in the care of the critically ill patients with imbalances of fluid, electrolytes and acid base imbalances. Lack of their knowledge about fluid, electrolytes imbalance is considered as barrier to provide the care for those patients this could be due to that these nurses have limited attention to nurses' continuing education or training programs especially about fluid, electrolytes imbalances. This result agrees with (Mogileeswari \& Ruth Grace, 2016) revealed that there is level of knowledge regarding fluid and electrolyte replacement therapy among 100 samples, $15(15 \%)$ have adequate knowledge, 62(62\%) have moderately adequate knowledge and 23(23\%) have inadequate knowledge.

The present study showed that the average high scores of good knowledge with bachelor degree of nurses. This level of knowledge of nurses' detect the need for nurses to be university graduates to reach the desired level of skills because nurses who receive 4 years of undergraduate education have the opportunity of working and thus gaining practical ability to reach professional maturity. This result agreed with (Ayes K., 2014) who found that the highest scores of studied nurses obtained by university graduates.

Regarding nurses experience it was found that less than one third of them had 5-10years of professional experience and $>10$ years one third. Looking at the average knowledge score by the duration of professional experience of nurses, it was found that the nurses had <5 $(34.6 \%)$ years of experience had the high score knowledge and practice. High level of knowledge and practice for the new nurses may be an indication of technological advances used both at schools and hospitals nowadays since they are used 
more efficiently.(Ayes, 2014) who showed that $57.4 \%$ of the nurses who were included in the study to determine the level of knowledge of intravenous fluid therapy were in the 23-27 age group, and the group between the ages of 18-22 got the highest results, also this result disagree with (Gunes \& Senol, 2010) reported that the majority of nurses with duration of employment of over 10 years found to have higher knowledge scores than nurses with work duration of below four years.

The results of present study showed there was more than three quarters of studied nurses had not study fluid, electrolytes and acid base imbalances undergraduate education. When examined the scores of nurses by the study of fluid, electrolytes and acid base imbalances under graduation, the scores of studied and not studied nurses were as follows respectively; $31.19 \pm 8.35,26.82 \pm 6.78$, As can understand from the findings of this study, the importance of introducing the concept of fluid, electrolytes and acid base in nursing curriculums to provide them with the needed information and competency to provide high quality nursing care for the patients.

(Ayse, 2014) found that 29.9\% of the nurses answered the question about the electrolytes in body fluids correctly by saying that "it allows to maintain body fluid osmolarity", while $36.6 \%$ of them give the false answer, and $33.5 \%$ did not answer the question. In the present study showed that the mean score of knowledge concern electrolytes $(10.98 \pm 4.47)$ with range $(2.0$ - 22.0).

The present study revealed that nearest to the half of studied nurses have poor knowledge this result disagree with Vijayan (2011) told that half of nurses have adequate knowledge, $47.5 \%$ of nurses have moderately adequate knowledge and the rest of nurses have inadequate knowledge. In addition, Scales \& Pilsworth (2012) told that nurses ${ }^{\text {ce }}$ knowledge regarding fluid balance should be improved because nurses are the primary persons responsible for the monitoring of the fluid balance.

This study showed that more than two thirds of studied nurses had good level of practice and (30.8\%) had fair level of practice regarding fluid, electrolytes and acid base imbalances. As well, Mogileeswari \& Ruth Grace, (2016) who found (37\%) safe practice $(42 \%)$ moderately safe practice and $(21 \%)$ have unsafe.

Regard fluid balance monitoring the mean score of practice $17.67 \pm 7.28$ with total score 22 and range 7.0 - 22.0, this result agreed with Diacon \& Bell, (2012) regarding Fluid balance calculation, More than two thirds reported that it was easy to manage fluid balance activities for patients. This result disagreed with Walker et al., (2015) twenty-six percent of nurses in the study agreed that it was difficult to supervise all the fluid balance activities because they may be responsible for more than one patient.

\section{Conclusion}

The results of this study found that the majority of studied nurses were at the age group of 25 to $<30$, females, married, and $58.5 \%$ were diploma degree. The general score of nurses' knowledge poor level of knowledge but the general score of nurses' practice were good. There were statistically significant difference between knowledge of studied nurses and their practice regarding fluid, electrolytes and acid base imbalance.

\section{Recommendations}

Provide education programs for nurses to improve nurses' performance regarding fluid, electrolytes and acid base balance.

\section{References}

1. Asfour A., (2016): Fluid Balance Monitoring Accuracy in Intensive care units, Journal of Nursing and Health Science, V(5), N (4), P.P 53-62.

2. Ayers P., \& Dixon C., (2012): Simple acidbase tutorial, Journal of Parenteral Enteral Nutrition, V (36), N (1), P.18.

3. Ayse K., (2014): International Association of social Science Research (IASSR), Evaluation of knowledge on intravenous fluid therapy of the nurses;v(5) N(4).

4. Boron W., \& Boulpaep E., (2012): Medical Physiology, third edition, chapter 5, Elsevier Inc. pages 628-630.

5. Bruno A., André L., Lívia M., Alexandre T., \& Marcelo P., (2015): Fluid and electrolyte overload in critically ill patients: World Journal of Critical Care Medicine, V(4)N(2): pages 116-129.

6. Davies A., (2010): How to perform fluid assessment in patients with renal disease. Journal of Renal Nursing V (2) N (2) page 7680.

7. Diacon A., \& Bell J., (2012): Investigating the recording and accuracy of fluid balance monitoring in critically ill patients. S Afr J Crit Care V(30) N(2) P.P 55- 57.

8. Eastwood, Glenn M., Peck, Leah, Young, Helen, Prowle, John, Vasudevan, Vandana, Jones, Daryl, \& Bellomo R., (2012): Intravenous fluid administration and monitoring for adult ward patients in a teaching hospital. Nursing \& health sciences V. (14) N.(2): pp. 265-271. 
9. Gunes, A., \&Senol, S., (2010): knowledge and practices of nurses concerning intravenous potassium administration, Australian Journal of Advanced Nursing, volume (32), number (1).

10. Kamil P., Regina B., Jaroslaw S., Aldona Z., \& Wladyslaw Wieczorek (2011): "The electrolyte characteristics"V(57): PP.58-65. Electrolyte - Wikipedia https://en.wikipedia. org/wiki/ Electrolyte

11. Mogileeswari P., \& Ruth M., (2016): Knowledge and practice regarding fluid and electrolyte replacement therapy for patient with burns. International Journal of Multidisciplinary Research and Development 2016; V (3)N(4):PP.217-220.

12. McMillen R., \& Pitcher B., (2010): The balancing act: Body fluids and protecting patient health. British Journal of Healthcare Assistants; $\mathrm{V}(5): \mathrm{N}(3)$, P.P117-121. https://www.nursingtimes

13. Scales K., \&Pilsworth J., (2012): The importance of fluid balance in clinical practice. Nursing Standard;V(22) N (47):Pages50-57.

14. Shepherd A., (2011): Measuring and managing fluid balance. Nursing Times ; V (107) N(28) Pages12-16.

15. Shier D., Butler J., \& Lewis R., (2010): Human Anatomy and Physiology, 12 edition, Chapter 21, copyright by McGraw-Hill companies, pages811-825.

16. Taylor C., Lillis C., Lynn P., \&Lemone P., (2015): Fundamentals of nursing, $8^{\text {th }}$ edition, chapter 3, Lippincott pages 1471-1484.

17. Verma A., \& Paul R., (2010): The interpretation of arterial blood gases Aust. Prescriber, V (33) pp. 124-129

18. Vijayan A., (2011): fluid and electrolyte administration, Journal of Nursing and Health Science,V(5),I(4), P.P 53-62.

19. Walker G., Stewart-Parker E., Chinthapalli S., Ostermann M., Dargan P., \& Wood D., (2015): Intravenous fluid use in the acutely unwell adult medical inpatient: improving practice through a clinical audit process. J $\mathrm{R}$ Coll Physicians Edinb V. (42) P.P211-215. 